\title{
Metamaterial Applicator for Hyperthermia Cancer Treatment Procedure: Overview Study
}

\author{
Vei Ling Wong ${ }^{(\bowtie)}(\mathbb{D}$ and Kasumawati Lias (D) \\ Faculty of Engineering, Universiti Malaysia Sarawak (UNIMAS), 94300 Kota Samarian, \\ Sarawak, Malaysia \\ veilingwong@gmail.com, lkasumati@unimas.my
}

\begin{abstract}
This paper presents an overview of metamaterial slabs or lens as an integrated structure for applicators used in hyperthermia cancer treatment procedure. Hyperthermia treatment procedure (HTP) is a new technique that exposes a cancerous tissue by increasing tissue temperature until $41{ }^{\circ} \mathrm{C}$ to $45{ }^{\circ} \mathrm{C}$ at a certain period with electromagnetic radiation. Based on the previous study, by moving the microwave sources relative to the metamaterial (MTM) lenses from a tumor/cancer phantom alters the concentration of heating within biological tissue. In this paper, the overview of a metamaterial study on HTP from 2009 to 2019 was carried out. This study indicated that the left-handed metamaterial (LHM) lens was observed to be able to improve the focusing capabilities of HTP on the treated tissue. However, a further study is significantly required to provide different focus position distances on the treated tissue for different stages of cancer. Therefore, a modified HTP applicator integration with an MTM lens structure was proposed. It is aimed to improve focus position distance on the treated tissue and to reduce unwanted hot-spots on surrounding healthy tissues simultaneously. The proposed modified structure was presented in this paper. Specific absorption rate (SAR) simulation was carried out with SEMCAD X 14.8.4 to obtain a SAR distribution for determining penetration depth and focusing position distance on the treated tissue.
\end{abstract}

Keywords: Metamaterial lens · Hyperthermia · Left-handed metamaterial · Specific absorption rate

\section{Introduction}

In recent years, hyperthermia treatment procedure (HTP) applicators for non-invasive HTP have been extensively studied. HTP, an alternative therapy for cancer [1], is often used as adjuvant therapy with chemotherapy and radiotherapy [2]. HTP is a technique to expose cancerous tissue with electromagnetic (EM) radiation in order to increase tissue temperatures within $41^{\circ} \mathrm{C}-45^{\circ} \mathrm{C}$ at a certain period. Based on the previous research, it was observed that this hyperthermia technique converts cancerous tissues into necrotic tissues and destroys cancerous tissues with minimal side effects [1, 3, 4].

Generally, HTP can be either invasive or noninvasive, depending on the location of HTP applicators, which are either inserted into or on the surface of the human body. 
Invasive HTP can be much more effective than a non-invasive HTP, as it is pointed and inserted directly to the targeted region [5]. However, invasive HTP can cause several adverse health effects, such as bleeding during minor surgery, which is required in treatment application.

Non-invasive HTP, adverse health effects can be minimized as it does not require minor surgery. Non-invasive HTP is simpler to handle than invasive HTP and is suitable for use as an in-situ applicator [1, 4]. However, poor penetration depth and focus position distance are the main drawbacks of noninvasive HTP.

In conjunction, MTM structure is integrated into the base antenna to form a modified HTP applicator. The main objective of this integration is to improve penetration depth and focus position distance on the treated tissue resulted from the existing HTP applicator.

\section{Metamaterial Applicator in HTP}

Current research proved that concentration of heating is adjustable by moving microwave sources with respect to MTM lenses based on tumor position [6,7]. MTM classification was first proposed by Veselago in 1968 as an artificial component, which consists of negative permittivity, $\varepsilon$ and permeability, $\mu$. This type of MTM is known as the lefthanded material (LHM) and acts as a negative refractive index (NRI) lens to induce electromagnetic field (EMF) from an energy source [8].

The two commonly used MTM structures are electrical dipoles or a thin wires array and the magnetic loops or split-ring resonators array (SRR) [9].

The thin wires array (Fig. 1 [a]) is also known as epsilon-negative (ENG) MTM. Through the parallel configuration of thin metallic wire meshes, ENG MTM will exhibits high-pass properties for the incoming plane waves. The wires are parallel to the electric field and perform a negative effect of permittivity below the plasma frequency. The wire can be made of silver, gold, aluminum, or copper [9].

Split-ring resonators (Fig. $1[\mathrm{~b}]$ ), the most used structure in designing mu-negative (MNG) MTM. An SRR cell, which consisted of two concentric metallic rings (either square or circle) forming an array structure by a specific gap, $d$. The gap between the inner and outer rings shows capacitive effects, while each ring itself becomes inductive. Thus, the integration of the two rings forms an LC resonance circuit [9].

ENG and MNG MTMs can be combined to form a double-negative (DNG) material (Fig. 1 [c]), which is known as negative refractive index (NRI) material. NRI materials contribute to the negative permittivity effect from wire arrays and negative permeability of SRR array [9].

DNG MTMs are frequency-dependent, which results in the refractive index $n$. This is explainable by Drude-Lorentz models, which are indicated in Eqs. 1, 2, and 3 [9].

$$
\begin{gathered}
n \equiv n_{\text {eff }}(\omega)=\sqrt{\varepsilon_{\text {eff }}(\omega) \mu_{\text {eff }}(\omega)} \\
\varepsilon_{e f f}(\omega)=1-\frac{\omega_{e p}^{2}-\omega_{e 0}^{2}}{\omega^{2}-\omega_{e 0}^{2}-j \omega \gamma_{c}} \\
\mu_{\text {eff }}(\omega)=1-\frac{F \omega^{2}}{\omega^{2}-\omega_{m 0}^{2}-j \omega \Gamma}
\end{gathered}
$$


where $\varepsilon_{e f f}(\omega), \mu_{e f f}(\omega), \omega_{e p}, \omega_{m p}, \omega_{e 0}, \omega_{m 0}, \gamma_{c}, F$, and $\Gamma$ are frequency-dependent effective permittivity, frequency dependent effective permeability, electric plasma frequency, magnetic plasma frequencies, electric resonant frequency, magnetic resonant frequency, collision frequency, amplitude factor and damping factor, respectively.

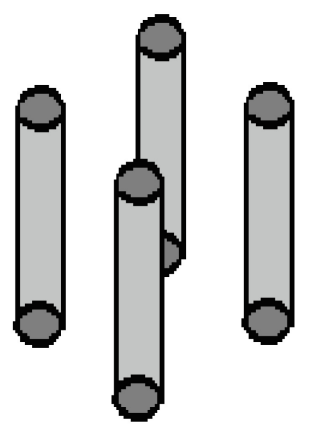

(a)

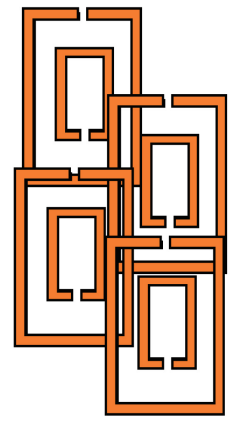

(b)

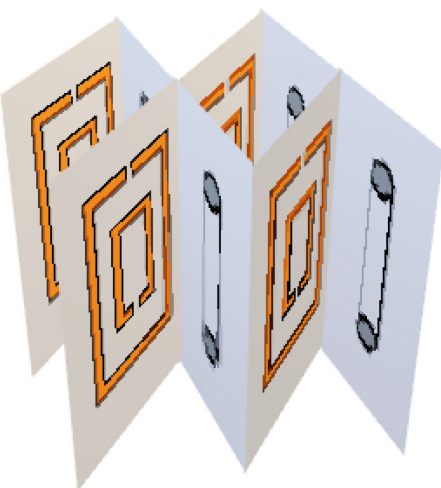

(c)

Fig. 1. (a) ENG, (b) MNG and (c) DNG structure

\subsection{Current MTM Slabs or Lens Research in HTP}

Since Pendry's publication titled negative refraction makes a perfect lens in the year 2000 [10], the investigation of NRI material was inspired. From [10], this perfect lens, or as mentioned by Pendry as "superlens", can be achieved with the microwave band of current technology [10,11]. In [11], Pendry's works were further elaborated, and the concept of MTM was implemented along with the introduces of the Pendry-Veselago slab lens. These investigations made it possible to obtain unique effects, such as imaging with subwavelength image resolution, which is generated through NRI that supports a host of surface plasmon states for both polarizations of light.

Thus, starting from this remarkable study, investigations on MTMs in antenna development have increased, as well as HTP for cancer treatment. This is because of perfect lens or more known as left-handed material (LHM) provides substantial EM energyfocusing capability on the treated tissue [12]. Table 1 presents an overview of MTM slabs or lens research from 2009 to 2019. 
Table 1. Overview of MTM slabs or lens researches

\begin{tabular}{|c|c|c|c|}
\hline $\begin{array}{l}\text { Published year and } \\
\text { reference }\end{array}$ & Type of structure & Targeted organ & Research finding(s) \\
\hline $2009,[13]$ & DNG - LHM slabs & Muscle & $\begin{array}{l}\text { When the source was moving } \\
\text { towards the LHM lens, the } \\
\text { heating depth was increased } \\
\text { Higher input power was } \\
\text { required to archive the } \\
\text { necessary therapeutic } \\
\text { temperature }\end{array}$ \\
\hline $2009,[14]$ & $\begin{array}{l}\text { Combination of dielectric } \\
\text { filling and metamaterial layer }\end{array}$ & Brain & $\begin{array}{l}\text { The combined structure } \\
\text { increased system response to } \\
\text { the relative movements of the } \\
\text { head around a geometrical } \\
\text { focal point }\end{array}$ \\
\hline $2010,[15]$ & DNG - $\Gamma$-Shaped LHM Lens & Breast & $\begin{array}{l}\text { Incoming sources were } \\
\text { applied to horizontal, vertical, } \\
\text { or both sides of } \Gamma \text {-shaped } \\
\text { LHM lens } \\
\text { The condition with only } \\
\text { single-sided sources reduced } \\
\text { hyperthermia performance }\end{array}$ \\
\hline 2011, [16] & $\begin{array}{l}\text { DNG- metallic slabs with } \\
\text { broadside-coupled split-ring } \\
\text { resonators }\end{array}$ & Breast & $\begin{array}{l}\text { SAR was focused on the } \\
\text { targeted tissue region }\end{array}$ \\
\hline $2014,[17]$ & $\begin{array}{l}\text { DNG - metamaterial zeroth } \\
\text { order (ZOR) mode resonator } \\
\text { (lumped LC circuit) }\end{array}$ & Muscle & $\begin{array}{l}\text { The proposed structure } \\
\text { generated good EM waves } \\
\text { penetration depth towards } \\
\text { biological tissue }\end{array}$ \\
\hline $2015,[7]$ & $\begin{array}{l}\text { DNG - single, double and } \\
\text { conformal four lens LHM } \\
\text { structure }\end{array}$ & Breast & $\begin{array}{l}\text { The conformal four-lens } \\
\text { showed better focusing } \\
\text { resolution and temperature } \\
\text { concentration within the tumor } \\
\text { than single and double lens } \\
\text { Due to poor longitudinal } \\
\text { resolution, single-lens LHM } \\
\text { could not achieve good } \\
\text { hyperthermia performance }\end{array}$ \\
\hline $2016,[18]$ & $\begin{array}{l}\text { DNG - metamaterial ZOR } \\
\text { mode resonator (lumped LC } \\
\text { circuit) }\end{array}$ & Muscle & $\begin{array}{l}\text { Composition of ZOR array } \\
\text { structures radiated EM waves } \\
\text { that were nearly plane waves } \\
\text { in structure } \\
\text { The shape of the heating } \\
\text { pattern was adjustable by } \\
\text { manipulating relative power to } \\
\text { ZOR structures }\end{array}$ \\
\hline $2019,[12]$ & $\begin{array}{l}\text { DNG - cylindrical and flat } \\
\text { LHM lens }\end{array}$ & Breast & $\begin{array}{l}\text { Cylindrical LHM lens showed } \\
\text { better focusing effect than flat } \\
\text { rectangular LHM lens }\end{array}$ \\
\hline
\end{tabular}

\section{Proposed Design}

The proposed design for this research is provided in Fig. 2. 


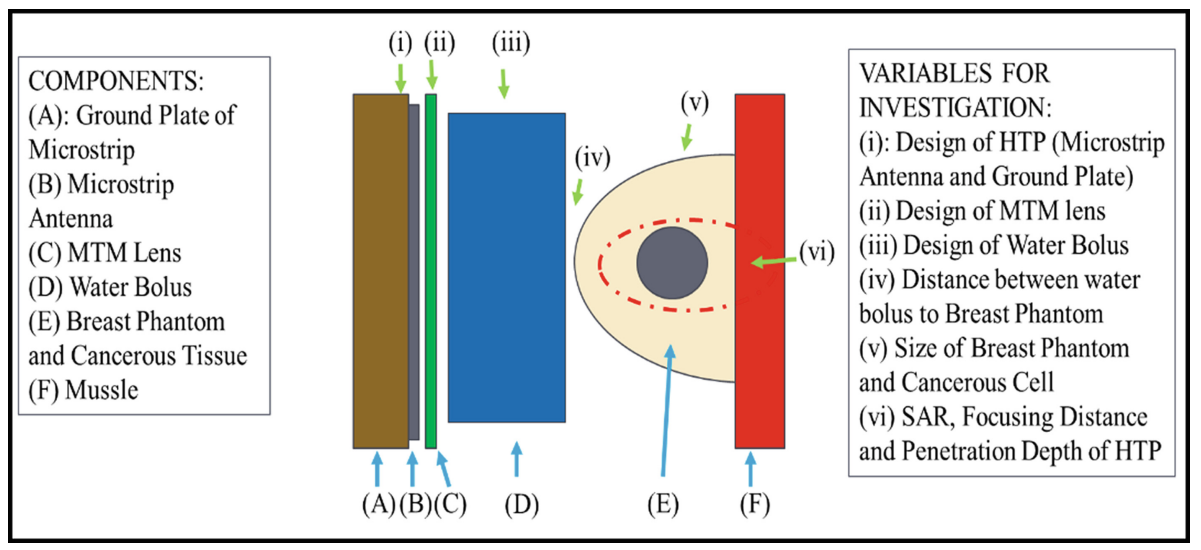

Fig. 2. Proposed modified HTP

As illustrated in Fig. 2, HTP applicator is a combination of two main components: microstrip antenna and MTM lens. Water bolus is then added to the treatment procedure to complement the HTP execution. The HTP applicator contributes an important role in the treatment as it is used to radiate thermal energy or heat to the targeted tissue. This HTP applicator is noninvasive, which applies externally to the human body.

Since this research experimentation is mainly conducted through simulation, the research tool, which is selected to be used is known as SEMCAD X 14.8.4 produced by SPEAG. SEMCAD $X$ is a highly specialized full-wave EMF solver used to design HTP applicators and determine radiation distribution, which presents the EM energy penetration depth and its energy focus distance.

Various MTM structures are investigated in order to observe the effects on the focus position distance on the treated tissue. SAR simulation is conducted to determine the penetration depth and focus position depth.

According to the standard of International Electrotechnical Commission (IEC) and Institute of Electrical and Electronics Engineers (IEEE), IEC/IEEE 62704-1, SAR can be calculated by Formulas 4, 5, and 6,

$$
S A R=\frac{\delta}{\delta t}\left(\frac{\delta W}{\rho \delta V}\right)
$$

When implemented to the electric field,

$$
S A R=\frac{\sigma E^{2}}{2 \rho}
$$

Therefore, based on electric field distribution, SAR can be related to the increase in temperature at a given point as in the formula below.

$$
S A R=\frac{c \Delta T}{\Delta t} \mid t=0
$$


where, $W, t, V, E, \rho, T, \sigma$, and $c$ stand for energy absorbed (W), time taken (sec), volume of element $\left(\mathrm{m}^{3}\right)$, peak electric field vector $(\mathrm{V} / \mathrm{m})$, density of element $\left(\mathrm{kg} / \mathrm{m}^{3}\right)$, temperature $\left({ }^{\circ} \mathrm{C}\right)$, conductivity of tissue $(\mathrm{S} / \mathrm{m})$, and specific heat capacity $\left(\mathrm{J} / \mathrm{kg}^{\circ} \mathrm{C}\right)$ respectively.

These modifications and integration processes are aimed at improving focus position distance at different stages of cancer.

\section{Conclusion}

HTP is an alternative treatment for cancer treatment procedure by using induced heat and form the biological effect. The effectiveness of HTP is significantly depended on focusing position distance of the energy in order to elevate the temperature of the cancerous tissue within $41^{\circ} \mathrm{C}-45^{\circ} \mathrm{C}$. HTP denatures cancerous tissues into necrotic tissues and destroys them with minimal side effects. In this overview study, MTM or LHM lens had shown a good capability to provide penetration depth and EM energy focus position distance on treated tissues. However, in terms of focus position distance, this technique needs improvement to cater to different stages of cancer. Thus, this research was carried out to introduce a modified HTP applicator that can improve focus position distance at different stages of cancer.

Acknowledgment. The authors would like to thank the Faculty of Engineering, Universiti Malaysia Sarawak for the support.

\section{References}

1. Lias, K.B., Zulkarnaen, M., Narihan, A., Buniyamin, N.: An antenna with an embedded EBG structure for non invasive hyperthermia cancer treatment. In: 2014 IEEE Conference on Biomedical Engineering and Sciences (2014). https://doi.org/10.1109/IECBES.2014.704 7577

2. Koo, Y.S., Kazemi, R., Liu, Q., Phillips, J.C., Fathy, A.E.: Development of a high SAR conformal antenna for hyperthermia tumors treatment. IEEE Trans. Antennas Propag. 62, 5830-5840 (2014). https://doi.org/10.1109/TAP.2014.2357419

3. Korkmaz, E., Isik, O., Kara, S.: Electromagnetic modeling of a female breast hyperthermia applicator. In: IEEE Antennas and Propagation Society, AP-S International Symposium (Digest), pp. 2048-2049 (2013). https://doi.org/10.1109/APS.2013.6711682

4. Sharma, N., Jain, B., Singla, P., Prasad, R.R.: Rectangular patch microstrip antenna: a survey. Int. Adv. Res. J. Sci. Eng. Technol. 1, 144-147 (2014). https://iarjset.com/wp-content/ uploads/2014/12/IARJSET15-a-pradeepsingla-RECTANGULAR-PATCH-MICRO-STRIPANTENNA-A-SURVEY.pdf

5. Wang, L., Yin, D., Li, M., Li, L.: Microstrip near-field focusing for microwave non-invasive breast cancer thermotherapy. In: 2014 31th URSI General Assembly and Scientific Symposium, URSI GASS 2014, pp. 1-4 (2014). https://doi.org/10.1109/URSIGASS.2014.693 0098

6. Jaffar, N.A., Lias, K.B., Madzhi, N.K., Buniyamin, N.: An overview of metamaterials used in applicators in hyperthermia cancer treatment procedure. In: 2017 International Conference on Electrical, Electronics and System Engineering, ICEESE 2017 2018-Janua, pp. 32-36 (2018). https://doi.org/10.1109/ICEESE.2017.8298389 
7. Leggio, L., De Varona, O., Dadrasnia, E.: A comparison between different schemes of microwave cancer hyperthermia treatment by means of left-handed metamaterial lenses. Prog. Electromagn. Res. 150, 73-87 (2015). https://doi.org/10.2528/PIER14101408

8. Freire, M.J., Marques, R.: Metamaterial focusing device for microwave hyperthermia. Microw. Opt. Technol. Lett. 53, 2868-2872 (2011). https://doi.org/10.1002/mop.26434

9. Wojciech, J.K., Thanh, N.C.: Metamaterials in application to improve antenna parameters, metamaterials and metasurfaces (chap 4). In: Josep, C.F. (ed.) IntechOpen (2019). https://doi. org/10.5772/intechopen.80636

10. Pendry, J.B.: Negative refraction makes a perfect lens. Phys. Rev. Lett. 85, 3966-3969 (2000). https://doi.org/10.1103/PhysRevLett.85.3966

11. Guenneau, S., Ramakrishna, S.A.: Negative refractive index, perfect lenses and checkerboards: trapping and imaging effects in folded optical spaces. Comptes Rendus Phys. 10, 352-378 (2009). https://doi.org/10.1016/j.crhy.2009.04.002

12. Jaffar, N.A., Lias, K., Madzhi, N.K., Buniyamin, N., Member, I.: Improving the performance of applicators for use in hyperthermia cancer treatment procedure by the introduction of LHM lens. Int. J. Electr. Electron. Syst. Res. 14, 697-705 (2019). https://jeesr.uitm.edu.my/ v1/IEESR/Vol.14/article5.pdf

13. Gong, Y., Wang, G.: Superficial tumor hyperthermia with flat left-handed metamaterial lens. Prog. Electromagn. Res. 98, 389-405 (2009). https://doi.org/10.2528/PIER09091401

14. Karathanasis, K.T., Gouzouasis, I.A., Karanasiou, I.S., Uzunoglu, N.K.: The use of left handed materials for the optimization of the focusing attributes of a biomedical hybrid system. In: 2009 International Symposium on Electromagnetic Compatibility - EMC Europe, pp. 1-4 (2009). https://doi.org/10.1109/EMCEUROPE.2009.5189679

15. Tao, Y., Wang, G.: Influence of source offset on breast tumor hyperthermia with $\Gamma$-shaped LHM lens applicator. 2010 International Conference on Microwave and Millimeter Wave Technology, ICMMT 2010, pp. 1859-1861 (2010). https://doi.org/10.1109/ICMMT.2010. 5524876

16. Velazquez-Ahumada, M.C., Freire, M.J., Marques, R.: Metamaterial applicator for microwave hyperthermia. In: 2011 30th URSI General Assembly and Scientific Symposium (2011). https://doi.org/10.1109/URSIGASS.2011.6050641

17. Vrba, D., Vrba, J., Stauffer, P.: Novel microwave applicators based on zero-order mode resonance for hyperthermia treatment of cancer novel microwave applicators based on zeroorder mode resonance for hyperthermia treatment of cancer. In: 2014 IEEE Benjamin Franklin Symposium on Microwave and Antenna Sub-Systems for Radar, Telecommunications, and Biomedical Applications (BenMAS) (2014). https://doi.org/10.1109/BenMAS. 2014.7529479

18. Vrba, D., Rodrigues, D.B., Vrba, J., Stauffer, P.R.: Metamaterial antenna arrays for improved uniformity of microwave hyperthermia treatments. Prog. Electromagn. Res. 156, 1-12 (2016). https://doi.org/10.2528/PIER16012702 